\title{
Comparative transcript profiling of gene expression between seedless Ponkan mandarin and its seedy wild type during floral organ development by suppression subtractive hybridization and CDNA microarray
}

\author{
Wen-Ming Qiu, An-Dan Zhu, Yao Wang, Li-Jun Chai, Xiao-Xia Ge, Xiu-Xin Deng and Wen-Wu Guo*
}

\begin{abstract}
Background: Seedlessness is an important agronomic trait for citrus, and male sterility (MS) is one main cause of seedless citrus fruit. However, the molecular mechanism of citrus seedlessness remained not well explored.

Results: An integrative strategy combining suppression subtractive hybridization (SSH) library with cDNA microarray was employed to study the underlying mechanism of seedlessness of a Ponkan mandarin seedless mutant (Citrus reticulata Blanco). Screening with custom microarray, a total of 279 differentially expressed clones were identified, and 133 unigenes (43 contigs and 90 singletons) were obtained after sequencing. Gene Ontology (GO) distribution based on biological process suggested that the majority of differential genes are involved in metabolic process and respond to stimulus and regulation of biology process; based on molecular function they function as DNA/RNA binding or have catalytic activity and oxidoreductase activity. A gene encoding male sterility-like protein was highly up-regulated in the seedless mutant compared with the wild type, while several transcription factors (TFs) such as AP2/EREBP, MYB, WRKY, NAC and C2C2-GATA zinc-finger domain TFs were down-regulated.
\end{abstract}

Conclusion: Our research highlighted some candidate pathways that participated in the citrus male gametophyte development and could be beneficial for seedless citrus breeding in the future.

Keywords: Citrus, cDNA microarray, Differential transcript, Male sterility-like protein, Seedlessness

\section{Background}

Seedlessness is a desired fruit trait for consumers, and a fruit is considered to be seedless if it produces no seeds, traces of abortion seeds, or significant reduced-number of seeds [1]. Some plants can set seeds asexually through apomixis. However, in most flowering plants, seed initiation requires signals activated by the double fertilization event that occurs in the embryo sac, and seed is produced sexually from the fertilized ovule [2,3]. Various phytohormones such as gibberellins (GAs), auxins and cytokinins are involved in this signaling process [4-6]. GAs and

\footnotetext{
* Correspondence: guoww@mail.hzau.edu.cn
Key Laboratory of Horticultural Plant Biology (Ministry of Education); National

*Correspondence: guoww@mail.hzau.edu.cn
Key Laboratory of Horticultural Plant Biology (Ministry of Education); National Key Laboratory of Crop Genetic Improvement, Huazhong Agricultural University, Wuhan 430070, China
}

(c) 2012 Qiu et al.; licensee BioMed Central Ltd. This is an Open Access article distributed under the terms of the Creative Commons Attribution License (http://creativecommons.org/licenses/by/2.0), which permits unrestricted use, distribution, and reproduction in any medium, provided the original work is properly cited. jasmonic acid/jasmonate derivatives (JAs) were found to play crucial roles in plant reproductive development $[7,8]$.

Citrus is one of the most important fruit crops with great economic and health value around the world [9]. However, some citrus varieties are seedy, and seedy fruits have constrained the development of fresh citrus market. Therefore, breeding seedless citrus varieties is a long-term pursuit for citrus breeders worldwide [10,11]. Nowadays, Satsuma mandarin and navel orange are two of the most famous and widely grown citrus varieties, mainly due to their seedless trait. For decades, great progress on seedless citrus breeding was made by traditional approaches such as sexual hybridization, seedling and bud sport mutation. However, due to the peculiarities of citrus reproductive biology such as long juvenile period and nucellar polyembryony, 
traditional breeding is inefficient and costly [12]. Modern biotechnological approaches (e.g. somatic hybridization) have potential to effectively expedite breeding process of citrus [13-15]. As most citrus varieties can produce fruits parthenocarpically [16], male or female sterility, embryo sac abortion, self-incompatibility, polyploidy and even environmental stress can result in seedless citrus fruits $[17,18]$. Actually there were some successful reports about seedless fruit production by genetic transformation. Ectopic expression of $\mathrm{iaaH}$ gene with $\mathrm{DefH} 9$ as promoter to elevate auxin levels in placenta or ovules resulted in seedless fruits $[19,20]$. Another effective strategy was by specific expression of toxin proteins during early development of plant reproductive organs. Typical cases were the ectopic transformation of the Barnase gene from Bacillus amyloliquefaciens $[21,22]$. Potential cases were by specific expression of enzymes such as chloroplast Chaperonin 21 and ubiquitin extension protein S27a to induce cell disruption of seed tissues for parthenocarpic plants [11,23,24]. And in our laboratory, the Arabidopsis thaliana MAC12.2 gene had been introduced into precocious trifoliate orange (Poncirus trifoliata [L.] Raf) for production of potential seedless fruits [25].

Male sterility (MS) is one of the main causes for seedless fruit production in citrus. In recent years, great progress on MS was made with annual plants especially rice [26,27], Arabidopsis [28] and oil-rape [29], and a serial of genes regulated tapetum, anther and pollen development were identified. However, there remained very limited information on MS of perennial woody plants such as citrus. Ponkan mandarin (Citrus reticulata Blanco) is a widely grown citrus variety in China. Within this variety, many variants were derived through sexual hybridization and mutation such as bud sport mutation. 'Qianyang seedless' Ponkan mandarin (QS) is an elite seedless variant selected from bud sport mutation of a common seedy Ponkan mandarin, and it can set fruits with no seeds (even no seed rudiments) in open orchard $[30,31]$. In this article, QS and a common seedy Ponkan mandarin 'Egan NO.1' (EG) were used for comparative study. These two mandarins shared highly close genetic relationship based on molecular marker analysis and showed no distinctly morphological differences except that QS was completely male sterile while Egan No 1 has normal flower. In order to gain general understanding on genes involved in this MS mutation, suppression subtractive hybridization (SSH) [32] combining with cDNA microarray was performed to detect differentially expressed genes. Several candidate genes and related pathways were focused in particular. Our research identified some useful genes which could be beneficial to citrus seedless breeding. The results could help to reveal the molecular mechanism of male sterility of Ponkan mandarin and shed light on seedless trait formation of other perennial woody plant at the gene expression level.

\section{Results}

Phenotype analysis of the floral organs of QS

Previous studies suggested that the floral organs (actually the whole plant) of QS had no morphological difference from the wild type. To further validate the phenotype of this seedless Ponkan mandarin, we measured the length of filament and pistil, and the average ratio of filament to pistil (filament length/pistil length) was $0.83 \pm 0.01$ for EG and $0.79 \pm 0.01$ for QS. And for EG, the pistil was $0.155 \pm 0.01 \mathrm{~cm}$ longer than filament while for QS, the pistil was $0.166 \pm 0.009 \mathrm{~cm}$ longer than filament. Above data further confirmed that the floral organs of both EG and QS had no morphological difference, and the seedless trait was not caused by malformation of reproductive organs. However, the number of pollen grains per anther of QS was 9.5\% less than that of EG. The pollen dying viability of QS was $6.0 \% \pm 1.0 \%$ (or $6.5 \% \pm 1.0 \%$ for $\mathrm{I}_{2}-\mathrm{KI}_{2}$ staining) in striking contrast to the high viability of $93.8 \% \pm 0.9 \%$ (or $89.6 \% \pm 2.5 \%$ for $\mathrm{I}_{2}-\mathrm{KI}_{2}$ staining) for EG. Pollen germination test found that no pollen of QS could germinate. Furthermore, SEM assays showed abnormal structures of the pollen grains of QS (Figure 1), confirming that QS is male sterile.

\section{Construction of SSH-CDNA libraries and overall feature of the differential transcript profiling}

To identify genes associated with the MS of QS, SSH cDNA libraries (both forward and reverse) were constructed from floral organs of QS and EG. A total of 6,048 cDNA clones derived from the SSH-cDNA libraries including 4,195 from the forward library and 1,853 from the reverse one were successfully amplified, and then used for a custom cDNA microarray. Each cDNA clone has triplicate spots on the array. The RNA samples of the four developmental stages (SF, MF, BF and OV) were used for array-hybridization. The fluorescent dyelabelled cDNA and hybridization strategy was employed for the microarray assay.

From the 6,048 clones printed on the glass slide, 279 cDNA clones (278 non-redundant) were differentially expressed (false discovery rate (FDR) $<0.05$ and a fold change $\geq 2$ ) between QS and EG. Among these cDNA clones, $218(78 \%)$ were down-regulated while only 61 (22\%) showed up-regulated expression across the four developmental stages; and the differentially expressed clones peaked at full bloom stage (BF) (Figure 2). At this stage, many more clones showed down-regulated than upregulated expression. During the four developmental stages, one clone (GenBank accession no. JU497336) encoding a putative cysteine protease (tr[B9RRA4]) showed 


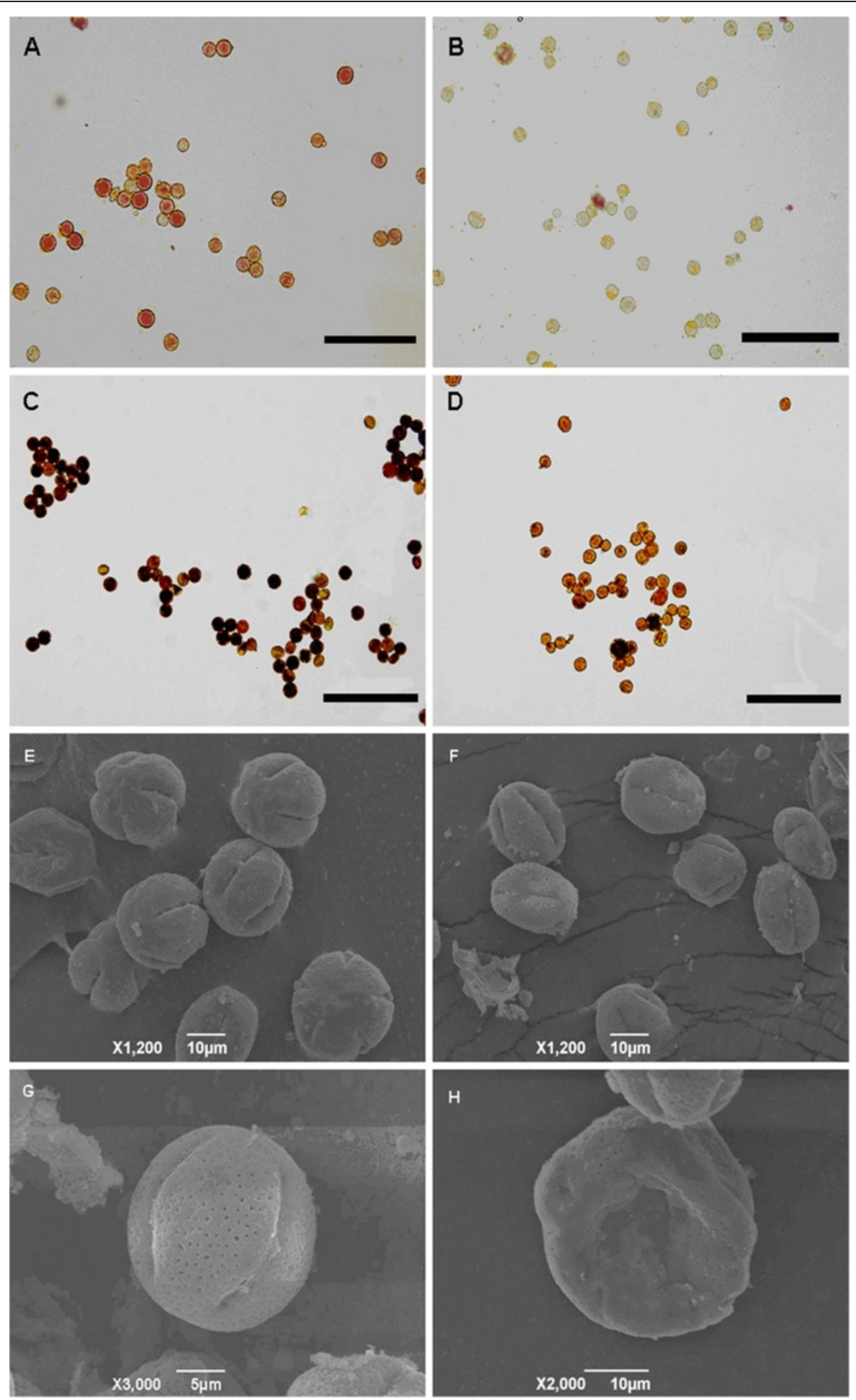

Figure $\mathbf{1}$ Viability assay and SEM analysis of pollen grains. A, C, E, G showed the pollen grains of EG; B, D, F, H showed the pollen grains of QS. Bar $(\mathbf{A}, \mathbf{B}, \mathbf{C}, \mathbf{D})=100 \mu \mathrm{m}$. 


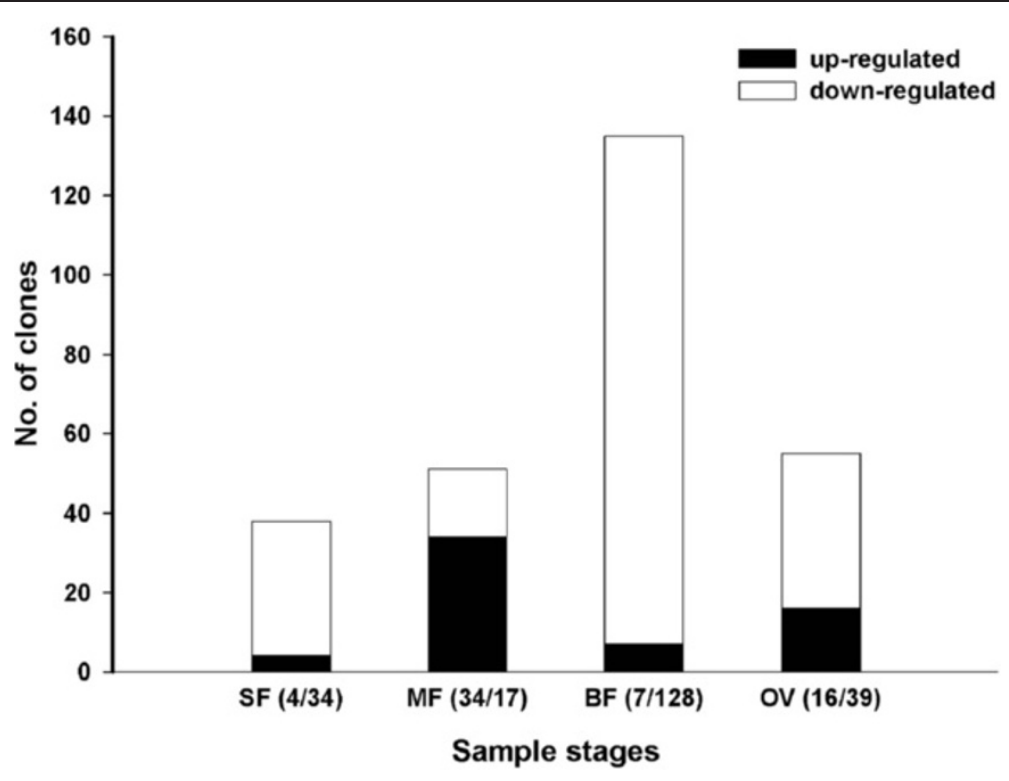

Figure 2 Number of clones significantly up- and down-regulated in QS during four developmental stages. Each two numbers in parentheses of $x$-axis indicated the numbers of clone up- and down-regulated respectively.

down-regulated expression at BF stage but up-regulated at OV stage (young ovaries of 2-3 days after flowering).

\section{Sequencing of the differentially expressed clones and EST analysis}

Among the 279 differentially expressed clones, 255 nonredundant clones were subjected to one single-pass sequencing. In all, 237 high-quality ESTs (average length was $496 \mathrm{bp}$ ) were yielded after eliminating vectors and unreliable sequences. These ESTs were assembled using CAP3 program, and 133 unigenes (43 contigs and 90 singletons) were obtained with sequence redundancy of $43.9 \%$. The majority of the contigs (38) contained $2-5$ ESTs, whereas only 5 contigs contained 6-11 ESTs, indicating an ideal normalization and subtraction. Of the 133 unigenes, 80 (60.1\%) showed differential expression at BF stage. Subsequently, BLASTX search of the UniProt database showed that 20 unigens (15.0\%) did not have significant hits $\left(E-v a l u e ~ \leq 1.0 \times \mathrm{e}^{-5}\right)$. However, when the 20 unigenes were used in BLASTN (E-value $\leq 1.0 \times \mathrm{e}^{-10}$ ) search of the Citrus clementina transcript database [33,34] with local Blast software (ftp://ftp.ncbi.nlm.nih.gov/blast/ executables/release/LATEST/), 17 genes had significant hits and high scoring pairs (HSP) showed high nucleotide identity. It suggested that these 20 unigenes were unique for citrus, and three of them were novel citrus genes.

Based on the microarray analysis, the relative expression profiles of all 255 ESTs were performed hierarchical clustering with cluster software (version 3.0). Four typical relative expression patterns were observed in QS versus EG at four developmental stages. Figure 3A and $3 \mathrm{~B}$ showed a group of clones down-regulated mainly at squaring stage (SF) and full bloom stage (BF), respectively, while the other two groups of clones were down/ up-regulated constitutively during the developmental stages (Figure 3C and 3D). In addition, candidate genes with putative function that could be important for the MS of QS were specifically collected (Table 1). It is noteworthy that $27.7 \%$ of the unigenes (not listed in the table) were only annotated as putative proteins or with no defined biological process besides $15 \%$ unigenes with no hits in the database.

GO annotations were conducted and three categories representing molecular functions, biological processes, and cellular components were assigned. Figure 4 showed the percentage distributions of GO terms (2nd level GO terms) based on biological process. It indicated that during the floral organ development, the majority of differentially expressed genes were involved in metabolic process $(46 \%)$ or responded to stimulus $(27 \%)$ and regulation of biological process (18\%). In addition, the other two GO categories (molecular functions and cellular components) were also generated (data not shown). In the molecular function category, large proportion of unigenes may have binding activity (59\%), catalytic activity (19\%), or oxidoreductase activity (11\%), while the cellular components consisted mainly of intracellular (57\%) and membrane (23\%).

\section{Metabolic pathways involved in formation of seedless fruit}

As large proportion of altered expressed genes were involved in varieties of metabolic processes. Based on the KEGG (Kyoto Encyclopedia of Genes and Genomes) 
A SF MF BF OV

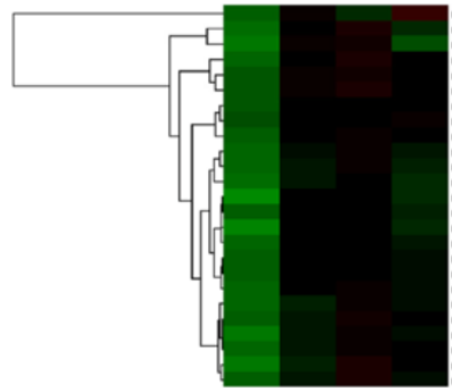

CS_P031_E-11_Predicted protein_triB9HWI7/

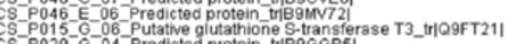

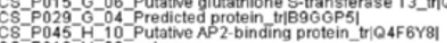

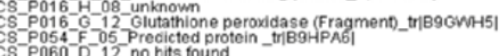

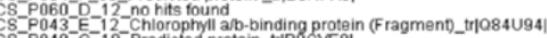

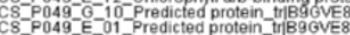

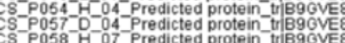

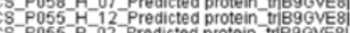

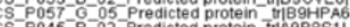

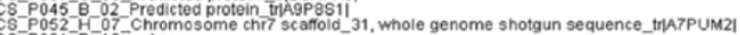

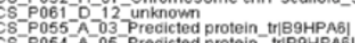

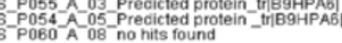

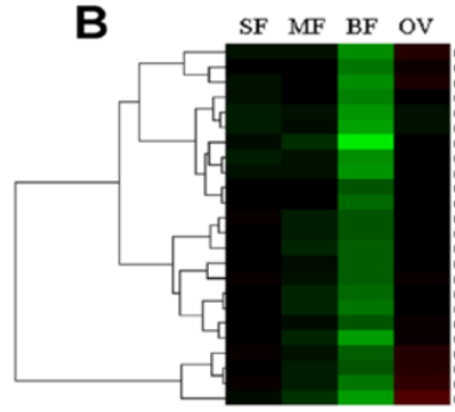

8 P003_F_ 07 AP2JERF domain-containing transcription factor_tragPLA1

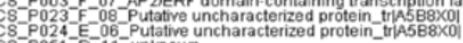

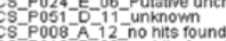

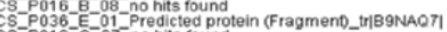

CS P016-C - $7^{-}$- no hits found

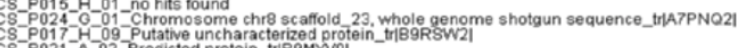

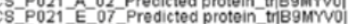

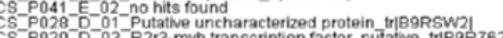

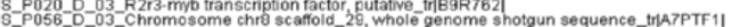

C8 062 -

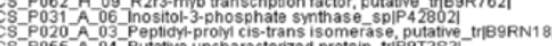

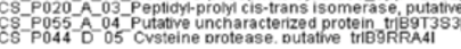
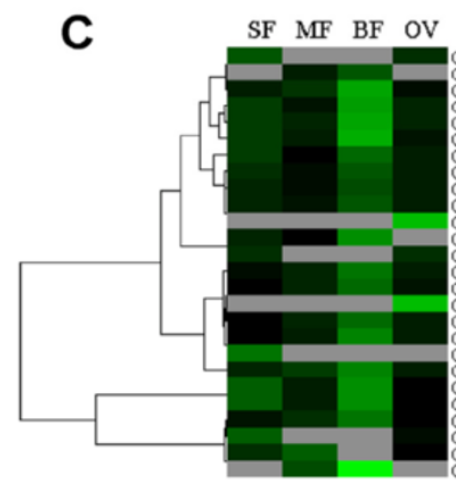

8035_ 03 Putative uncharacterized protein (Frogment) triB

CS P041- -06 - no hits found

CS-P002- 04 - CBFDREB-like transcription factor 1 triB3ROD7

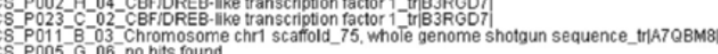

Pos.-06-no hits round

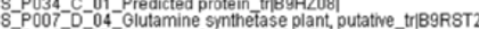

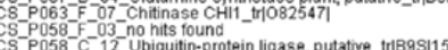

C

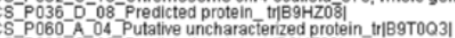

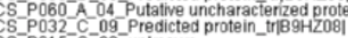

SP056-E- 05 - Predicted protein_triB9GVE

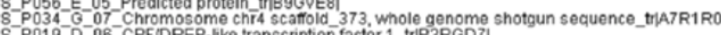

P019-0 - CBFIDREB-like transcription factor 1_triB3RGD

(1)

SP050-COT-Ubiquitin-protein ligase, putative_tr|BgS115

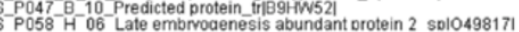
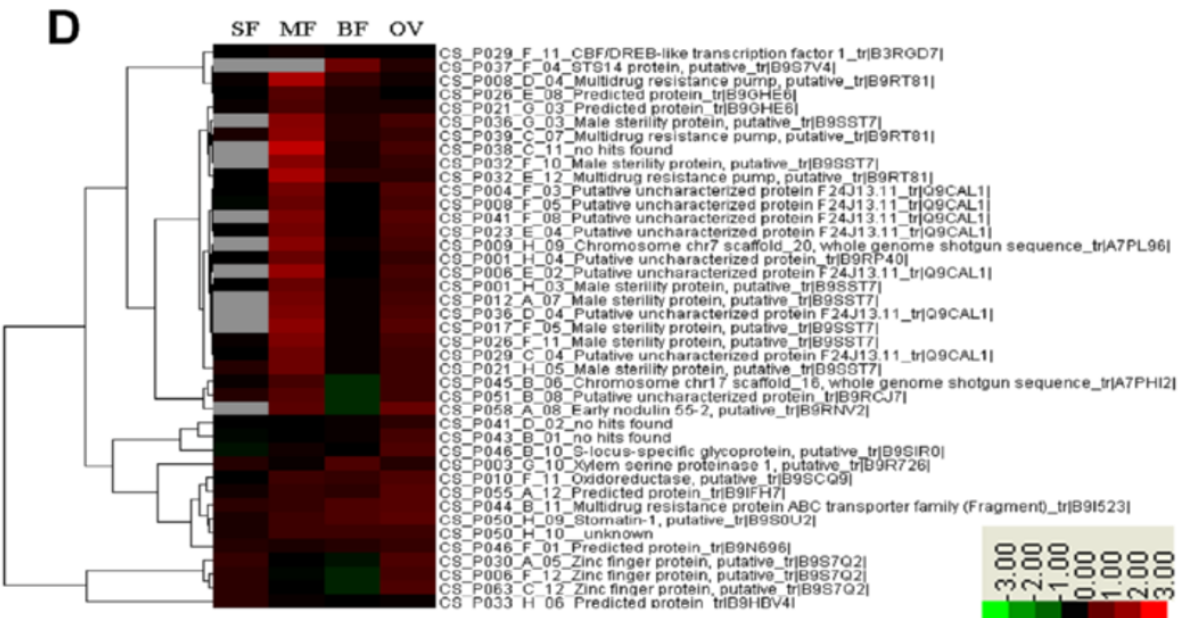

Figure 3 (See legend on next page.) 
(See figure on previous page.)

Figure 3 Cluster analysis of expression profiles of altered expressed genes in the QS versus EG. A showed a cluster of ESTs that were down-regulated mainly at squaring stage (SF) when the tetrads were produced and the microsporocyte underwent meiosis. B showed ESTs that were down-regulated especially at full bloom stage (BF). C and D suggested a cluster of ESTs that were down-regulated and up-regulated constitutively during the four developmental stages respectively. The ratio value was log2 transformed for each gene and used for the

hierarchical clustering analysis.

analysis, 36 different metabolic pathways were altered during the four developmental stages. Among these pathways, nine $(25 \%)$ were related to amino acid metabolic pathway (Table 2), and genes involved in carbohydrate and energy metabolism showed down-regulated expression during subsequent developmental stages of floral organs. Besides, genes related to specific secondary metabolism such as terpenoids and polyketides metabolism were also found to be altered. Interestingly, a gene (JU497309) encoding fatty acyl-CoA reductase, which may be involved in lipid metabolic process, was identified (Table 1). This gene was found highly homologous with putative male sterile protein (GI: 255576327) in castor bean, fatty acyl-CoA reductase 3 (GI: 359500474 ) in poplar and male sterile 2-like protein (MS2) (GI: 3549681) in Arabidopsis. Herein, this gene was named as male sterile-like protein. And qRT-PCR analysis showed its expression level increased from SF to BF stages and then declined at OV stage. The expression pattern was similar in both QS and EG; however, it showed obviously higher expression level in QS than in EG during the developmental process (Figure 5).

\section{Differential expression of transcription factor genes}

It is noteworthy that among the 133 unigenes, 12 were assigned to the category of transcription factor (TF) based on plant TF database (http://planttfdb.cbi.edu.cn/). Figure 6 showed the specific expression pattern of six AP2-ERF family TFs, two zinc-finger TFs, one MYB TF and one NAC TF using qRT-PCR assay. These TFs (except of NAC TF) had similar expression profile during the four developmental stages between EG and QS. For instance, among six AP2-ERF TFs, four (AP2-EREBP TF1, AP2-EREBP TF3, AP2/ERF domain containing TF2 and CBF/DREB-like TF) showed co-expression pattern like "V" type. It showed that the gene expression level in QS was higher than that in EG from SF stage to MF stage; however, these genes were subsequently repressed more obviously in QS from MF stage to BF stage, and the gene expression level was down-regulated mostly at BF stage. Two zinc-finger TFs (GATA TF8 and Cys2-His2 type) and one R2R3-MYB TF likewise showed similar "V" typevariation tendency. The other two AP2-ERF TFs (AP2EREBP TF2 and AP2/ERF domain containing TF1) showed "V"-like type expression pattern in QS. However, the expression pattern of AP2/ERF domain containing
TF1 was somehow different from others, as it showed relatively stabilized expression level during the four stages in EG. As for NAC TF, its expression level was downregulated obviously at $\mathrm{BF}$ and $\mathrm{OV}$ stages in QS compare with EG. It was notable that no expression was observed at OV stage in QS. The results suggested that these TFs could play important roles in the seedless phenotype formation, and the relative expression level in QS versus EG seemed to be key factor in this process.

\section{Verification of microarray data}

Two approaches were used to examine the quality of the microarray data. First, as one contig was assembled by several ESTs that were arrayed at random location in the microarray, so these ESTs sharing similar sequence or encoding the same gene would share similar expression pattern. Additional file 1: Figure S1 showed that four ESTs (F2-13 G, F6-15I, F7-18O, F8-12A) were assembled into one unigene (JU497321) which encoded methionine synthase, and these four ESTs truly shared similar expression pattern. For the other approach, qRT-PCR was performed on 11 unigenes using gene-specific primer pairs. Expression patterns were compared at the four developmental stages between QS and EG. Additional file 2: Figure S2 showed the correlation analysis of the ratio values of differential expression level from microarray to that from qRT-PCR. Linear regression [(average microarray ratio value $)=a($ RRT-PCR value $)+b]$ analysis showed a good coefficient of variation $\left(R^{2}=0.847\right)$. These results confirmed the reliability of the microarray data.

\section{Discussion}

Here, we combined SSH and microarray techniques to investigate potential mechanism underlying seedlessness in Ponkan mandarin. SSH was proved to be an efficient and popular approach to enrich and identify differentially expressed genes between wild-type and its mutant or treatment $[35,36]$. However, because of high sensitivity of SSH, usually a large number of clones could be obtained but inevitably included some false-positive ones. Screening the SSH libraries to identify some candidate genes using microarray and to validate using qRTPCR has proved to be a high-throughput and efficient way [37-39]. However, relatively few clones were isolated in this study. Of the 6,000 clones, only 279 cDNA clones 
Table 1 List of selected candidate functional genes related to the formation of the phenotype of QS

\begin{tabular}{|c|c|c|c|c|}
\hline GenBank accsession no. & $\mathrm{EMI}^{\mathrm{a}}$ & Description $^{b}$ & e-Value $^{c}$ & Clones $^{d}$ \\
\hline \multicolumn{5}{|l|}{ Up-regulated } \\
\hline JU497309 & B9SST7 & Male sterility protein & $2 \mathrm{E}-77$ & 7 \\
\hline JU497311 & B9S7V4 & STS14 protein & $6 \mathrm{E}-23$ & 3 \\
\hline JU497315 & Q5CD81 & (E)-beta-ocimene synthase & $1 \mathrm{E}-120$ & 2 \\
\hline JU497324 & B9RXQ0 & Tryptophan synthase beta chain & $6 \mathrm{E}-91$ & 2 \\
\hline JU497327 & B9RT81 & Multidrug resistance pump & $5 E-50$ & 3 \\
\hline JU497333 & B9S7Q2 & Zinc finger protein & $1 \mathrm{E}-67$ & 3 \\
\hline JU497348 & A9ZN18 & Geranyl-diphosphate synthase & $3 \mathrm{E}-11$ & 5 \\
\hline JU497417 & B9R726 & Xylem serine proteinase 1 & $7 \mathrm{E}-24$ & 1 \\
\hline$J U 497359$ & B9SCQ9 & Oxidoreductase & $2 \mathrm{E}-36$ & 1 \\
\hline JU497418 & A1ECJ7 & Putative miraculin-like protein 2 & $7 E-24$ & 1 \\
\hline JU497422 & A9XCN2 & Putative DNA binding protein & $2 \mathrm{E}-24$ & 1 \\
\hline JU497389 & B91523 & Multidrug resistance protein $A B C$ transporter family & $1 \mathrm{E}-121$ & 2 \\
\hline JU497397 & B9SIRO & S-locus-specific glycoprotein & $2 \mathrm{E}-45$ & 1 \\
\hline$J \cup 497403$ & B9SOU2 & Stomatin-1, putative & $1 \mathrm{E}-07$ & 1 \\
\hline \multicolumn{5}{|l|}{ Down-regulated } \\
\hline JU497308 & B957Q1 & Zinc finger protein & $1 \mathrm{E}-140$ & 2 \\
\hline JU497318 & B9S1E9 & Transcription factor AtMYC2 & $4 \mathrm{E}-20$ & 2 \\
\hline JU497321 & B2VQEO & Methionine synthase & $1 \mathrm{E}-107$ & 4 \\
\hline JU497323 & P42802 & Inositol-3-phosphate synthase & $1 \mathrm{E}-112$ & 4 \\
\hline JU497331 & B9SR02 & Multicopper oxidase & $6 \mathrm{E}-78$ & 2 \\
\hline JU497332 & B3RGD7 & CBF/DREB-like transcription factor & $6 \mathrm{E}-44$ & 4 \\
\hline JU497336 & B9RRA4 & Cysteine protease & $2 \mathrm{E}-25$ & 2 \\
\hline JU497338 & Q8VWL8 & Beta-mannosidase & $6 \mathrm{E}-64$ & 2 \\
\hline JU497342 & 082547 & Chitinase $\mathrm{CHI} 1$ & $8 \mathrm{E}-28$ & 7 \\
\hline JU497343 & O49817 & Late embryogenesis abundant protein & $2 \mathrm{E}-22$ & 2 \\
\hline JU497344 & B9SI15 & Ubiquitin-protein ligase & $2 \mathrm{E}-54$ & 2 \\
\hline JU497351 & A9PLA1 & AP2/ERF domain-containing transcription factor & $2 \mathrm{E}-46$ & 1 \\
\hline$J \cup 497352$ & B9T724 & GATA transcription factor & $4 \mathrm{E}-62$ & 1 \\
\hline JU497353 & B9RZK6 & Protein COBRA & $4 \mathrm{E}-82$ & 1 \\
\hline JU497354 & A2IB54 & Mitogen-activated protein kinase & $4 \mathrm{E}-85$ & 1 \\
\hline JU497356 & B9RST2 & Glutamine synthetase plant & $3 \mathrm{E}-71$ & 1 \\
\hline JU497357 & Q3KN68 & Isoflavone reductase-like protein 5 & $2 \mathrm{E}-56$ & 1 \\
\hline JU497361 & B9SQM6 & Transcription factor & $3 E-34$ & 1 \\
\hline JU497362 & Q9FT21 & Putative glutathione S-transferase T3 & $2 \mathrm{E}-07$ & 1 \\
\hline JU497364 & B9GWH5 & Glutathione peroxidase (Fragment) & $2 \mathrm{E}-25$ & 1 \\
\hline JU497367 & B9RN18 & Peptidyl-prolyl cis-trans isomerase & $3 E-54$ & 1 \\
\hline JU497368 & B9R762 & R2R3-myb transcription factor & $1 \mathrm{E}-69$ & 1 \\
\hline JU497369 & 082547 & Chitinase $\mathrm{CHI} 1$ & $8 \mathrm{E}-28$ & 1 \\
\hline JU497419 & P83948 & Pectinesterase-3 & $1 \mathrm{E}-46$ & 1 \\
\hline JU497372 & B9NBQ9 & AP2/ERF domain-containing transcription factor & $1 \mathrm{E}-108$ & 1 \\
\hline JU497373 & Q9ZRC9 & ACC oxidase & $6 \mathrm{E}-36$ & 1 \\
\hline JU497421 & A5YWA9 & NAC domain protein & $1 \mathrm{E}-51$ & 1 \\
\hline JU497378 & Q7Y066 & Plasma membrane $\mathrm{H}^{+}$-ATPase & $1 \mathrm{E}-114$ & 1 \\
\hline
\end{tabular}


Table 1 List of selected candidate functional genes related to the formation of the phenotype of QS (Continued)

\begin{tabular}{|c|c|c|c|c|}
\hline JU497423 & B9RIP3 & Hevamine-A & $1 \mathrm{E}-22$ & 1 \\
\hline JU497424 & B9T0Z2 & ADP/ATP carrier protein & $1 \mathrm{E}-06$ & 1 \\
\hline JU497427 & Q84U94 & Chlorophyll a/b-binding protein (Fragment) & $2 \mathrm{E}-14$ & 1 \\
\hline JU497388 & A7XUL4 & dehydration-responsive element binding protein & $1 \mathrm{E}-14$ & 1 \\
\hline JU497391 & Q4F6Y8 & Putative AP2-binding protein & $6 \mathrm{E}-15$ & 1 \\
\hline JU497398 & Q6EV47 & Non-specific lipid-transfer protein (Fragment) & $1 \mathrm{E}-45$ & 1 \\
\hline JU497401 & B9SJL5 & Amine oxidase & $1 \mathrm{E}-57$ & 1 \\
\hline JU497405 & B9S925 & Zinc finger protein & $3 \mathrm{E}-88$ & 1 \\
\hline JU497406 & B9T868 & Putative peroxidase C3 (Fragment) & $8 \mathrm{E}-26$ & 1 \\
\hline JU497434 & Q8H2A1 & Caffeoyl CoA O-methyltransferase (Fragment) & $3 \mathrm{E}-11$ & 1 \\
\hline JU497412 & B9HGW6 & Glutaredoxin & $6 \mathrm{E}-20$ & 1 \\
\hline$J U 497413$ & B9R762 & R2R3-myb transcription factor & $3 E-21$ & 1 \\
\hline
\end{tabular}

${ }^{a}$ The EMI codes of the most similar genes to the EST sequences.

${ }^{\mathrm{b}}$ The description of sequences based on Uniprot database.

' The best e-value from a BLASTx search for corresponding EST sequences.

${ }^{d}$ The number of sequenced clones in the libraries.

were identified as differentially expressed. Such results may suggest that there were little variations between QS and EG mandarins in gene expression. It was hypothesized that bud sport mutant was likely caused by single gene mutation, DNA methylation or retroelement activity $[40,41]$. In this research, various types of DNA markers including SCAR [42], and SSR (172 pairs of primers), MSAP (96 pairs of primers) and AFLP (13

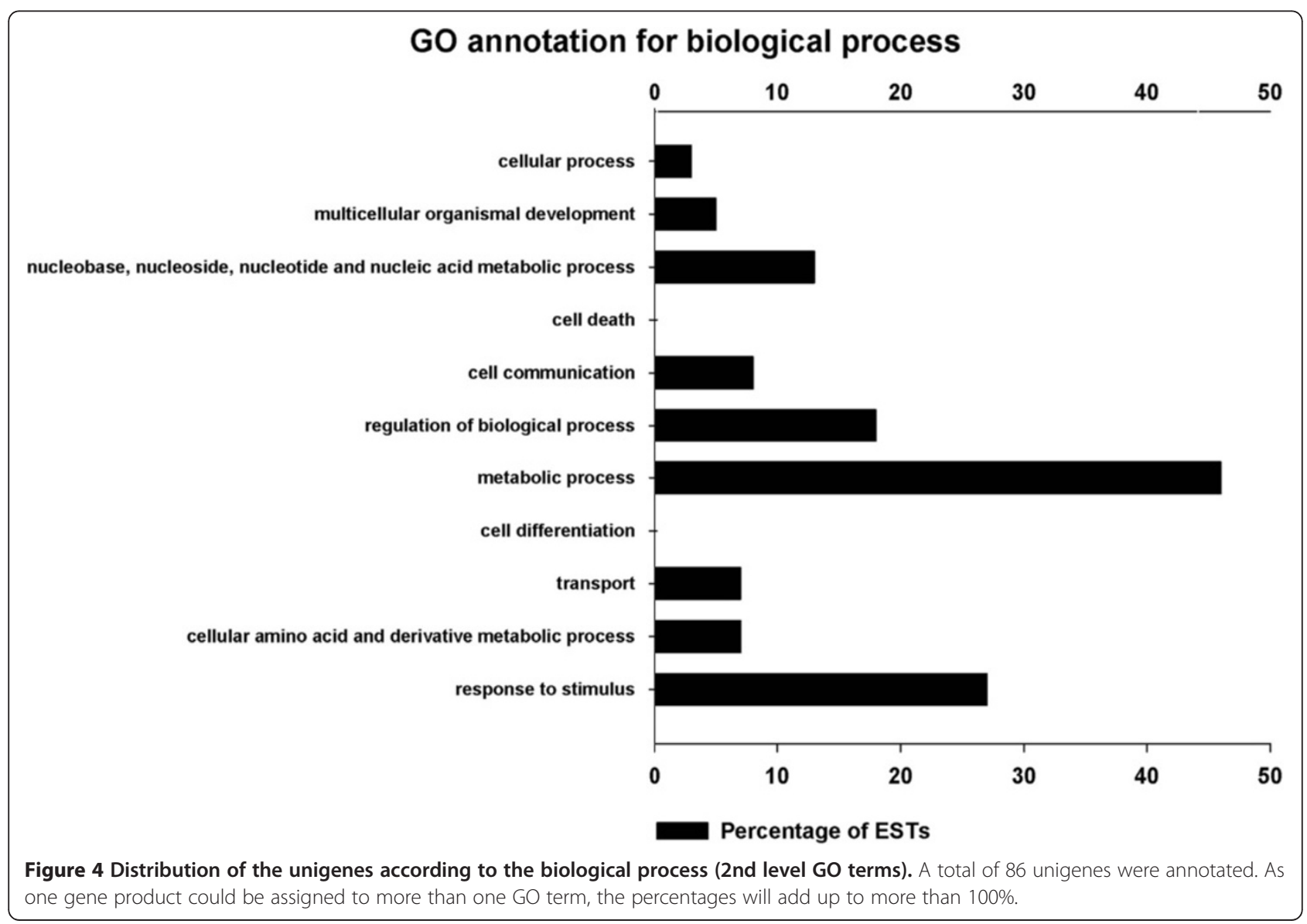


Table 2 List of differentially expressed genes involved in amino acid, carbohydrate, energy, terpenoid and polyketides metabolism based on KEGG pathway database

\begin{tabular}{|c|c|c|c|c|c|c|}
\hline \multirow{2}{*}{$\begin{array}{l}\text { KEGG } \\
\text { pathways }\end{array}$} & \multirow{2}{*}{$\begin{array}{l}\text { EC } \\
\text { number }\end{array}$} & \multirow[t]{2}{*}{ Putative function } & \multicolumn{4}{|l|}{ QS/EG } \\
\hline & & & SF & MF & $\mathrm{BF}$ & OV \\
\hline \multicolumn{7}{|c|}{ Amino acid metabolism } \\
\hline JU497356 & 6.3.1.2 & Glutamate-ammonialigase & $0.71 \pm 0.03$ & $0.84 \pm 0.05$ & $0.50 \pm 0.01$ & $0.79 \pm 0.03$ \\
\hline JU497374 & 6.3.5.4 & Asparagine synthase & $0.50 \pm 0.03$ & $1.15 \pm 0.08$ & $1.20 \pm 0.09$ & $1.02 \pm 0.06$ \\
\hline JU497373 & 1.14.17.4 & Aminocyclopropane carboxylate oxidase & $0.90 \pm 0.02$ & $1.52 \pm 0.05$ & $0.52 \pm 0.03$ & $1.15 \pm 0.09$ \\
\hline \multirow[t]{2}{*}{ JU497321 } & 2.1.1.14 & 5-methyltetrahydropteroyltriglutamate & $1.62 \pm 0.11$ & $0.97 \pm 0.08$ & $0.50 \pm 0.02$ & $0.90 \pm 0.08$ \\
\hline & & -homocysteine-methyltransferase & & & & \\
\hline JU497330 & 4.2.1.78 & (S)-norcoclaurine synthase & $1.04 \pm 0.11$ & $1.94 \pm 0.28$ & $1.29 \pm 0.04$ & $1.17 \pm 0.13$ \\
\hline JU497338 & 3.2.1.21 & Beta-glucosidase & $0.94 \pm 0.08$ & $\mathbf{0 . 4 7} \pm 0.04$ & $\mathbf{0 . 1 8} \pm 0.01$ & $0.88 \pm 0.17$ \\
\hline \multirow[t]{2}{*}{ JU497364 } & 1.11.1.1 & Phospholipid-hydroperoxide & $0.53 \pm 0.04$ & $0.97 \pm 0.10$ & $0.97 \pm 0.05$ & $1.08 \pm 0.01$ \\
\hline & & -glutathione peroxidas & & & & \\
\hline JU497324 & 4.2.1.20 & Tryptophan synthase & $1.86 \pm 0.13$ & $2.64 \pm 0.16$ & $1.03 \pm 0.05$ & $0.70 \pm 0.05$ \\
\hline JU497377 & 2.4.1.12 & Indole-3-acetatebeta-glucosyl transferase & $0.51 \pm 0.01$ & $1.51 \pm 0.04$ & $1.25 \pm 0.02$ & $\mathbf{0 . 4 8} \pm 0.04$ \\
\hline \multicolumn{7}{|c|}{ Carbohydrate metabolism } \\
\hline JU497385 & 3.2.1.14 & Chitinase & $1.15 \pm 0.15$ & $1.28 \pm 0.05$ & $1.00 \pm 0.17$ & $\mathbf{0 . 4 5} \pm 0.02$ \\
\hline JU497313 & 1.13.99.1 & Inositol oxygenase & $1.04 \pm 0.09$ & $1.08 \pm 0.04$ & $0.79 \pm 0.07$ & $\mathbf{0 . 4 9} \pm 0.03$ \\
\hline$J U 497323$ & 5.5.1.4 & Inositol-3-phosphate synthase & $1.11 \pm 0.08$ & $1.17 \pm 0.20$ & $\mathbf{0 . 4 8} \pm 0.03$ & $1.42 \pm 0.13$ \\
\hline JU497357 & 1.3.1.45 & 2\{prime\}-hydroxy isoflavone reductase & $1.10 \pm 0.05$ & $1.28 \pm 0.07$ & $\mathbf{0 . 4 4} \pm 0.01$ & $1.17 \pm 0.04$ \\
\hline \multicolumn{7}{|c|}{ Energy metabolism } \\
\hline JU497406 & 1.11.1.7 & Peroxidase & $0.99 \pm 0.05$ & $1.02 \pm 0.01$ & $1.12 \pm 0.09$ & $\mathbf{0 . 5 4} \pm 0.06$ \\
\hline JU497378 & 3.6.3.6 & Proton-exporting ATPase & $0.99 \pm 0.05$ & $0.90 \pm 0.02$ & $0.51 \pm 0.02$ & $0.94 \pm 0.03$ \\
\hline \multicolumn{7}{|c|}{ Terpenoids and polyketides metabolism } \\
\hline JU497376 & 1.1.1.295 & Momilactone-Asynthase & $1.42 \pm 0.54$ & $1.09 \pm 0.20$ & $1.05 \pm 0.03$ & $1.10 \pm 0.10$ \\
\hline JU497315 & 4.2.3.15 & Myrcene synthase & $1.24 \pm 0.04$ & $\mathbf{2 . 2 8} \pm 0.16$ & $0.52 \pm 0.01$ & $1.10 \pm 0.11$ \\
\hline JU497325 & 4.2.3.20 & (R)-limonene synthase & $1.27 \pm 0.18$ & $0.91 \pm 0.03$ & $0.50 \pm 0.02$ & $1.10 \pm 0.17$ \\
\hline
\end{tabular}

pairs of primers) were employed to analyze the polymorphism between these two mandarins, and no repeatable polymorphic bands were detected (data no shown). These results suggested that very few nuclear genes were altered during the developmental stages.

For the four developmental stages we chose, immense efforts were taken to determine which time-point was pivotal for stamen development, but there has no criteria for citrus gametophyte development. Though criteria for gametophyte development was available in model plant Arabidopsis [43], it can not be directly applied herein. Semi-thin and paraffin sections were performed in this study to survey the microsporogenesis of QS, and it was found that abnormal tetrads produced at the tetrad stage and subsequently the microsporocyte underwent abnormal meiosis. This process mainly occurred at SF stage (the diameter of floral organs is about $3 \mathrm{~mm}$ ) (unpublished data). Additionally, large proportion (about 59.7\%) of differentially expressed genes was found in BF when the anthers and pollen grains were almost mature, indicating that this time-point might be also important.

\section{Amino acid metabolic process}

Of the metabolic pathways with altered expressed genes, $25 \%$ were involved in amino acid metabolism. Amino acids were not only primary metabolic products for normal growth and development but also cell signaling molecules and regulators of gene expression and protein phosphorylation cascade [44]. Interestingly, among these amino acid metabolism pathways, two genes were downregulated across the developmental stages in QS versus EG, one (JU497356) encoding glutamate-ammonialigase (EC 6.3.1.2), the other (JU497338) encoding betaglucosidase (EC 3.2.1.21). In higher plants, glutamateammonialigase catalyzes ATP-dependent conversion of glutamate and ammonia into glutamine which occupies a central position of amino acid metabolic pathway [45], and this metabolic process is critical for coordinating 


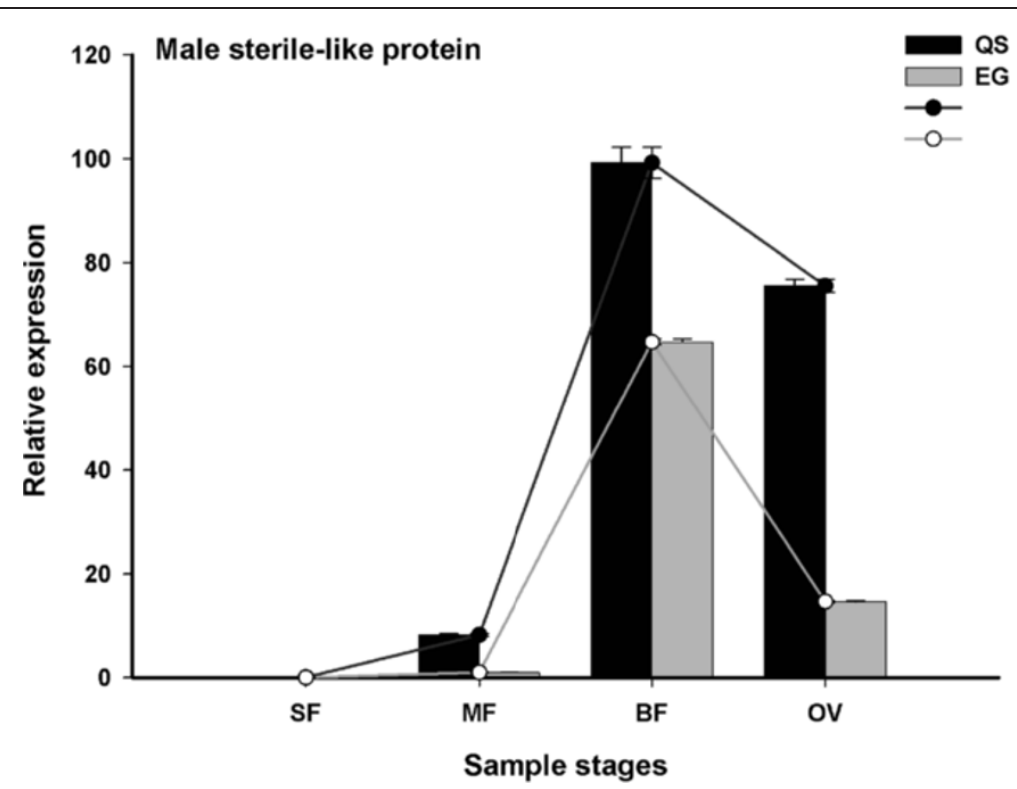

Figure 5 Relative expression (y-axis) of male sterile-like protein in QS versus EG during four developmental stages (x-axis) by qRT-PCR. Columns and bars represent the means and standard errors $(n=3)$ respectively.

metabolic balance in rice [46]. And beta-glucosidase could be used for the cellulosic ethanol industry [47] and has diversity of functions in plants. In maize, $\mathrm{Zm}$ p60.1 encoding a beta-glucosidase could release active cytokinin, and might function in vivo to supply the developing maize embryo [48]. Additionally, some betaglucosidases affect the properties of cell wall [49] and are associated with freezing tolerance, such as the SFR2 in Arabidopsis [50]. Some beta-glucosidases are related to the efficiency of microspore embryogenesis [51]. It is noteworthy that a gene (JU497374) encoding asparagine synthase (EC 6.3.5.4) was down-regulated exclusively at SF (early stage of stamen development). And asparagine is one central intermediate in nitrogen assimilation and transportation in plant [52,53]. Recent studies showed that this gene played important role in defense against pathogens and salt stress [54,55]. Additionally, genes related to carbohydrate metabolism and energy metabolism also showed down-regulated expression in QS mainly at BF and OV (late stage of stamen development). These results suggested that the vital activities of QS weakened during early development stages of stamen, and the metabolic process of nutrition and energy was also impaired at subsequent stages of stamen development especially when the stamen was mature.

Two genes involved in cysteine/methionine metabolism and participated in the biosynthesis of ethylene were also identified in this study. One (JU497321) encodes 5-methyltetrahydropteroyltriglutamate-homocysteine Smethyltransferase (EC 2.1.1.14) is likely involved in the biosynthesis of L-methionine. And the methionine can be transformed into S-adenosylmethionine (SAM) (the precursor of ethylene) [56]. The other one (JU497373) encodes aminocyclopropane carboxylate oxidase (EC 1.14.17.4) and is a pivotal enzyme during the biosynthesis of ethylene. In addition, genes involved in the synthesis of IAA (indole-3-acetic acid) were also identified such as a gene (JU497377) encoding Indole-3-acetatebeta-glucosyltransferase (EC 2.4.1.121). These results implied that the endogenous phytohormones might be involved in the male gametophyte development of citrus.

\section{Transcription factors}

It was known that floral organ formation and function were influenced by TFs regulation. In our research, twelve unigenes were assigned to the category of transcription factor, and six of them were identified as AP2ERF family members. AP2-ERF TF containing highly conserved AP2/ERF DNA-binding domain, is a large family unique in plant. In our research, four AP2-ERF members showed similar expression pattern. AP2EREBP TF1 was closely homologous with atERF107 (AT1G19210). This gene was likely involved in the regulation of gene expression by stress factors and by components of stress signal transduction pathways. However, until now, no experimental evidence was available. AP2-EREBP TF3 showed high similarity with ERF5 (AT5G47230.1). ERF5 might play an important role in plant innate immunity likely through coordinating chitin and other defense pathways [57]. Other research suggested that ERF5 and ERF6 might potentially overlap in their function and acted as positive regulators of JA/ethylene-mediated defense [58]. In tomato, this gene was mainly involved in responses to drought and salt stresses [59]. As for AP2/ERF 


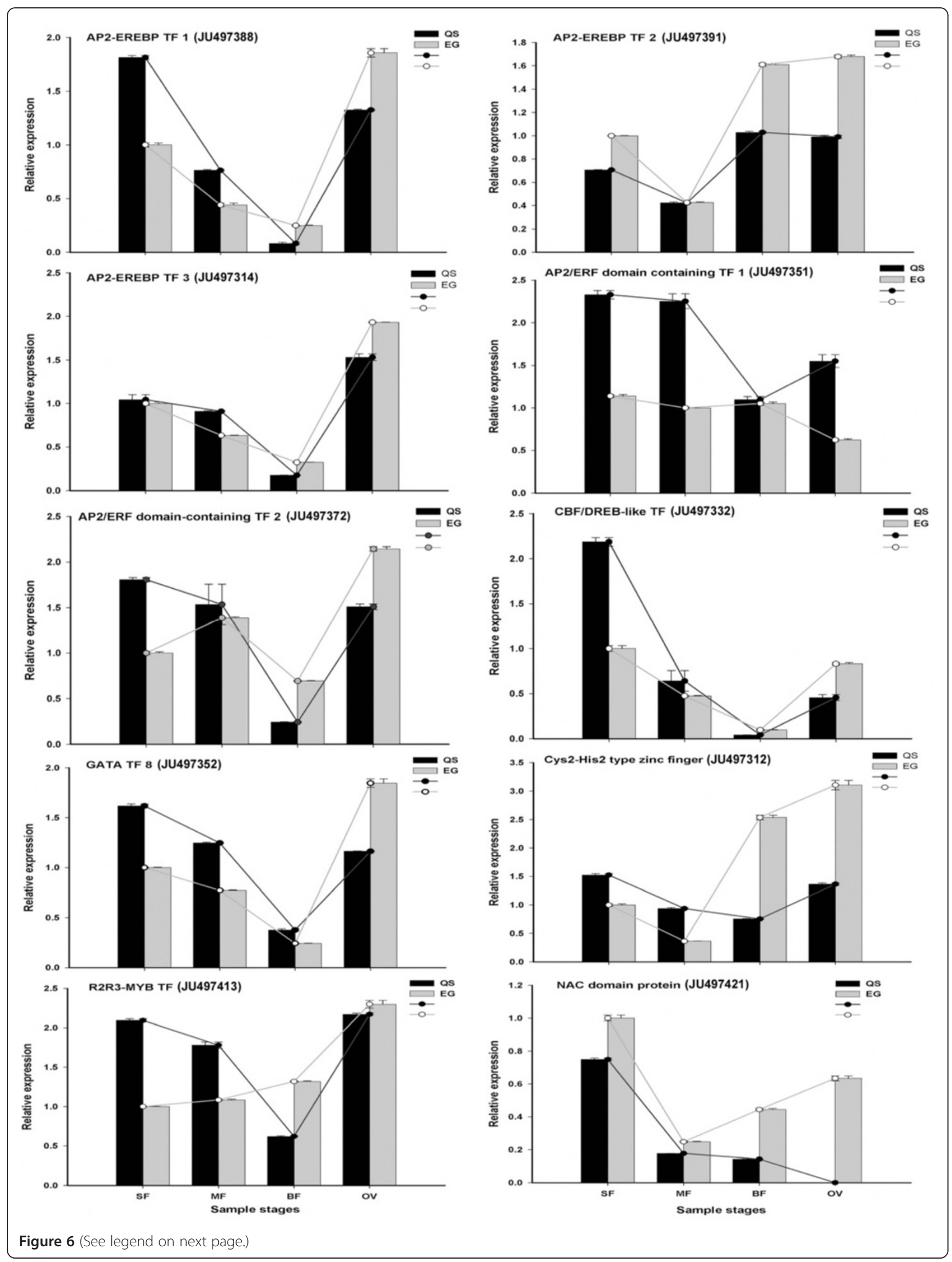


(See figure on previous page.)

Figure 6 Relative expression pattern of six AP2-ERF family TFs, two zinc-finger TFs, one MYB family TF and one NAC domain TF. The accession number of each TF was given inside the parenthesis. Relative expression was defined as the expression level in QS versus EG. Columns and bars represent the means and standard errors $(n=3)$ respectively.

domain containing TF2, its closest relative was ERF104 (AT5G61600.1). Recent studies showed that ERF104 was in vivo substrate of MPK6, and ethylene could release ERF104 and allow liberated ERF104 to access target genes related to plant defense [60]. CBF/DREB-like TF was of high similarity with CBF4 (AT5G51990.1) which was critical regulator involved in cold acclimation and drought adaptation [61,62].

In addition, AP2-EREBP TF2 was highly homologous with RAP2.4 (AT1G78080.1). RAP2.4 acted at or downstream of a converging point of light and ethylene signaling pathways, and it coordinately regulated multiple developmental processes and stress responses [63]. As for AP2-ERF domain containing TF1, its expression pattern was different from other five members. It showed high similarity with DREB26 (AT1G21910.1). In plant, RAP2.6, RAP2.6 L, DREB26 and DREB19 exhibited tissue specific expression and participated developmental processes as well as biotic and/or abiotic stress signaling [64]. Though previous researches emphasized the functions of these AP2-ERF TFs on resistance against biotic and abiotic stresses, AP2-ERF TFs were also participated in plant development such as embryo patterning [65], and stamen emergence [66].

Additionally, two MYB (R2R3-MYB) transcription factors also showed differential expression between QS and EG. In plant, MYB TF family was categorized into 3 subfamilies according to the number of adjacent repeats of MYB-domain. Of them, R2R3-MYB subfamily contains the largest number of members. Like the AP2-ERF TF family proteins, MYB family proteins also function in various plant-specific processes. In Arabidopsis, MYB TFs were found as key regulators involved in development, metabolism and biotic and abiotic stress responses. Among these MYB TFs of Arabidopsis, AtMYB26 is involved in determining endothecial cell development within the anther and is essential for anther dehiscence [67]. AtMYB33 and AtMYB65 redundantly facilitate anther and pollen development [68]. AtMYB80 regulates exine formation and acts downstream of AtMYB35; and AtMYB103 is required for tapetal development and microsporogenesis, especially for callose dissolution and exine formation [69,70]. AtMYB125 positively control male germ cell division and commit progenitor germ cells to sperm cell differentiation [71,72]. In rice, CSA gene encoding MYB TF functions as a key transcriptional regulator for sugar partitioning during male reproductive development, and the CSA mutant showed reduced levels of sugars and starch in floral organs which lead to MS.

Interestingly, in our results, one MYB TF showed similar expression pattern with AP2-ERF TFs that downregulated at BF stage when the anther and pollen grains are mature. This MYB TF termed as R2R3-MYB TF was closely related to ATMYBR1/ATMYB44 (AT5G67300.1), and AtMYB44 was likely to enhance drought and salt stress tolerance by suppressing the expression of genes encoding PP2Cs, which was described as negative regulators of ABA signaling [73]. Previous report showed that AtMYB44 was with changed expression during late embryogenesis and seed maturation [74]. And notably there was a NAC domain protein (JU497421) highly homologous with ANAC102 (AT5G63790.1). ANAC102 was an important regulator of seed germination and activated a seed-specific subset of genes under low-oxygen stress; it was also necessary for the viability of Arabidopsis seeds following low-oxygen treatment [75].

In summary, these results suggested that these AP2ERF TFs and the MYB TF functioned redundantly and coordinated with other TFs which involved in the complex network regulating floral organ development. Further research should emphasize on the isolation of proteins interacted with these TFs.

\section{Conclusion}

An integrative approach combining SSH and microarray was employed to explore the transcriptional changes of a seedless bud sport mutant of Ponkan mandarin. A number of differentially expressed genes were identified. And the majority of genes were down-regulated in the mutant, especially those related to basic metabolic process. Metabolism of nutrition and energy might be impaired during male gametophyte development of the mutant, and TFs and phytohormones might play important regulatory roles during this process. Our research gained general information of citrus MS at transcription level and could provide some clues for further exploration of MS in citrus species.

\section{Methods}

\section{Accession numbers of sequences and microarray data}

All the sequences generated in the study were deposited in GenBank with accession numbers from JU497308 to JU497435. Five sequences which are shorter than $200 \mathrm{bp}$ longer than $100 \mathrm{bp}$ are attached in Additional file 3. 
Microarray data and experimental information from this study were deposited in the Gene Expression Omnibus (http://www.ncbi.nlm.nih.gov/geo/) under accession number GSE38094.

\section{Plant materials and phenotype analyses}

Two Ponkan mandarin (Citrus reticulata Blanco) cultivars, Qianyang seedless (QS, mutant type) and Egan NO.1 (EG, a common seedy Ponkan mandarin, wild type) were grown in the same orchard of 'Fenghuangshan' citrus production area in the city of Dangyang, Hubei province, China. These two scion cultivars were seven years old when sampling in 2010, with trifoliate orange (Poncirus trifoliata L. Raf.) as the rootstock. Flower samples were collected from both cultivars in parallel including 4 continuous phonologically developmental stages (Figure 7C): squaring stage (SF, about $20 \mathrm{DBF}$ ), medium bud stage (MF, about $10 \mathrm{DBF})$, flowers at full bloom stage (BF) and young ovaries of 2-3 days after flowering (OV). All the flowers were bagged to prevent cross-pollination, and when sampled in the field, all the samples were frozen in liquid nitrogen as quickly as possible and then stored at $-80^{\circ} \mathrm{C}$ until needed.

The morphology of mature anthers were investigated with fluorescence stereo-microscope (Figure 7A; 7B) (Leica MZ FLIII, German) and image was captured with a digital camera (Nikon Coolpix, Japan). The pollen grain number per anther was counted. In brief, anthers from mature flowers were collected and mixed randomly, each time 40 anthers were dissected and pollen grains were suspended in $25 \mathrm{~mL}$ sterile water with 4-5 drops of surfactant (Tween-20, Amresco solon, $\mathrm{OH}$ ). The viability of mature pollen grains were evaluated by dying with $1 \%$ acetic acid magenta as well as $1 \%$ iodine potassium iodide $\left(\mathrm{I}_{2}-\mathrm{KI}_{2}\right)$ solution. After staining for 5 min, pollen grains were observed using BX-61 fluorescence microscope (Olympus, Japan) and Images were captured with DP70 CCD digital camera system. At least 1,000 pollen grains were counted. These experiments were repeated three times. The morphology of pollen grains was examined by scanning electron microscope (SEM) (NTC JSM-6390LV, Japan). For SEM, anthers at various developmental stages were pre-fixed with $2.5 \%$ glutaraldehyde in $0.1 \mathrm{M}$ sodium phosphate buffer $(\mathrm{pH} 7.2)$ for $24 \mathrm{~h}$, dehydrated twice using a gradient ethanol serial (30\%-50\%-70\%-85\%-95\%-100\%), then replaced ethanol with isopentyl acetate for $20 \mathrm{~min}$. After that, samples were dried with critical-point drying method then sputtered coating with gold. Representative images were captured.

\section{RNA extraction and mRNA isolation}

The materials (floral organs) for RNA extraction were sampled from at least six independent plants, and mixed randomly. Total RNA from flower samples at four stages (SF, MF, BF and OV) were extracted with modified Trizol method according to [76]. The RNA pellets were washed with $75 \%(\mathrm{~V} / \mathrm{V})$ ethanol twice, dissolved in RNase-free water and stored at $-80^{\circ} \mathrm{C}$ until use. By mixing equal amount of RNA of the four stages, RNA pools from both
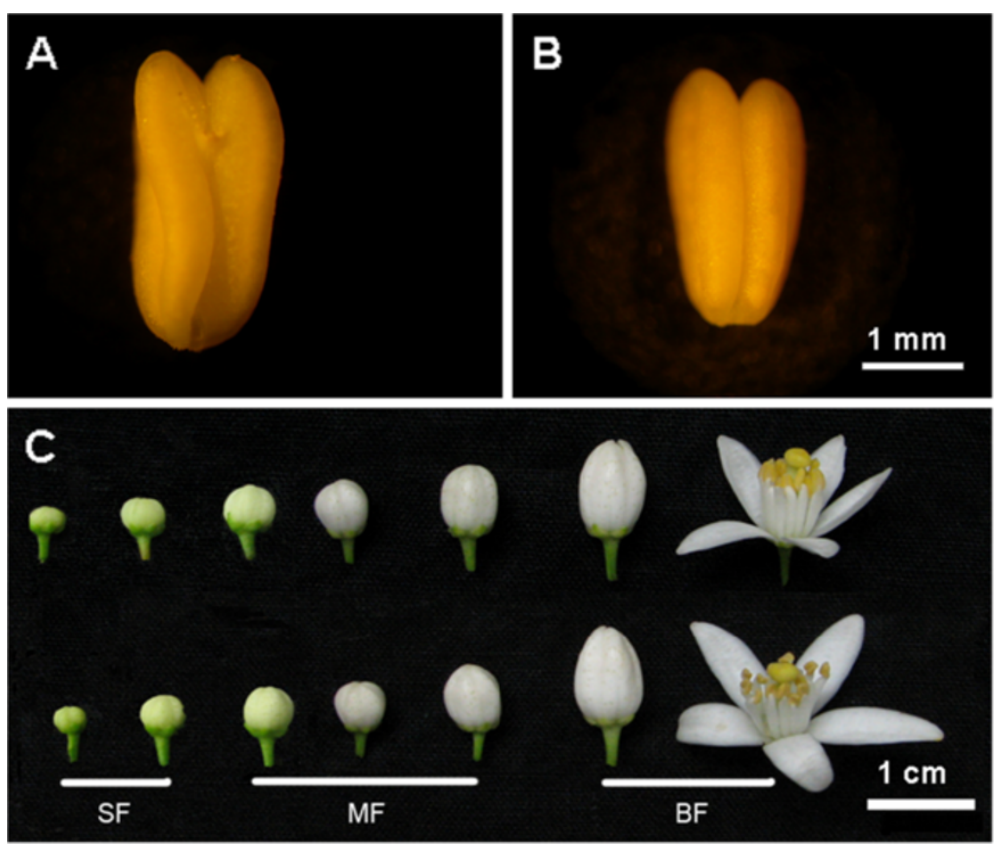

Figure 7 Flower organs at different developmental stages and mature anthers. A, B showed the anthers of EG and QS respectively; C showed the flower organs including SF, MF, BF stages, the upper row was EG. 
QS and EG were established in parallel. Then mRNA was isolated from each of the RNA pools using the Oligotex mRNA mini kit (Qiagen, Germany). The quality of RNA was determined by Nanodrop 1000 spectrophotometer (Thermo Scientific, Wilmington, DE, USA) and 1.2\% agarose gel electrophoresis.

\section{Suppression subtractive hybridization (SSH) CDNA libraries construction and cDNA inserts amplification}

Two micrograms of mRNA was used to synthesize cDNA for suppression subtractive hybridization (SSH). The SSH was performed with the PCR-select ${ }^{\mathrm{TM}}$ cDNA subtraction kit (Clontech, Palo Alto, CA, USA) according to the user manual. And both forward (the seedless cultivar QS as tester and the seedy cultivar EG as driver) and reverse (EG as tester while QS as driver) SSH were conducted. For cDNA libraries construction, two hybridizations were performed followed by two rounds of PCR amplifications to enrich the desired differentially expressed sequences. Then the second PCR-amplified cDNAs were purified and ligated into the T/A cloning vector pMD18-T (Takara, Japan) overnight at $4^{\circ} \mathrm{C}$. Then the ligated products were transformed into Electro MAX ${ }^{\mathrm{TM}} \mathrm{DH} 5 \alpha-\mathrm{E}^{\mathrm{TM}}$ cells (Invitrogen, USA) and incubated at $37^{\circ} \mathrm{C}, 160 \mathrm{r} / \mathrm{m}$ for $1 \mathrm{~h}$, then cultured on $\mathrm{SOB}-\mathrm{MgCl}_{2}$ solid media with ampicillin $\left(60 \mu \mathrm{g} \mathrm{ml}^{-1}\right)$ to generate the primary cDNA libraries. The transformed white bacteria were randomly picked and grown on 384-well plates containing Luria Broth (LB) liquid media with ampicillin $\left(100 \mu \mathrm{g} \mathrm{ml}^{-1}\right)$ at $37^{\circ} \mathrm{C}$ overnight (about 16 h). Glycerol (Amresco, USA) (4.4\% final) was added for storage at $-80^{\circ} \mathrm{C}$.

A total of 8,000 cDNA clones were randomly picked from forward and reverse SSH libraries and used as for subsequent PCR templates. Each PCR was performed in a $100 \mu \mathrm{l}$ reaction mixture using nested primers of SSH according to [77]. The PCR products were precipitated with equal amount of isopropyl alcohol and washed with $75 \%(\mathrm{~V} / \mathrm{V})$ ethanol, then re-suspended in $40 \mu \mathrm{l}$ sterile water. The yield and quality of the PCR products were determined by Nanodrop 1000 spectrophotometer (Thermo Scientific, Wilmington, DE, USA), and then run on 1.2\% agarose gel and examined by Bio-Rad UV spectroscopy (Bio-Rad Laboratories, Washington, DC, USA) to confirm single clone (Additional file 4: Figure S3). Finally the validated PCR products were stored at $-80^{\circ} \mathrm{C}$ for custom microarray.

\section{Microarray slides fabrication and preparation of fluorescent dye-labelled cDNA}

About 40 microlitre of PCR products were re-precipitated by adding $100 \mu \mathrm{l}$ of anhydrous ethanol and were dissolved in EasyArray ${ }^{\mathrm{TM}}$ spotting solution (CapitalBio Corp, China) at a final concentration of 0.1-0.5 $\mu \mathrm{g} \mathrm{\mu l}{ }^{-1}$ and then printed on amino-silaned glass slides with a SmartArrayer ${ }^{\mathrm{TM}}$ microarrayer (CapitalBio Corp). Each clone was printed triplicate. The particular procedures for microarray fabrication were conducted according to [37].

The relative gene expression profiles of QS at four developmental stages (SF, MF, BF and OV) compared with the corresponding four stages of EG were investigated by microarray analysis. For each stage, three sets of total RNA samples were extracted independently, and then RNA pool was constructed by mixing aliquot of RNA from the three sets of RNA samples. An aliquot of $5 \mu \mathrm{g}$ total RNA from the RNA pool was used to produce Cy5/Cy3-labelled cDNA employing an RNA amplification combined with Klenow enzyme labeling strategy according to the protocol by [78]. Cy5/Cy3-labelled cDNA was hybridized with the microarray at $42^{\circ} \mathrm{C}$ overnight. Hybridization was performed in duplicate by dye swap (Cy5-labelled cDNA of QS versus Cy3-labelled cDNA of EG, and Cy5-labelled cDNA of EG versus Cy3labelled $\mathrm{CDNA}$ of QS). And then the arrays were washed with $0.2 \% \mathrm{SDS}, 2 \times \mathrm{SSC}$ at $42^{\circ} \mathrm{C}$ for $5 \mathrm{~min}$, and $0.2 \% \mathrm{SSC}$ for $5 \mathrm{~min}$ at room temperature.

\section{Microarray data analysis and EST sequence analysis}

Arrays were scanned with a confocal laser scanner, LuxScan $^{\mathrm{TM}}$-scanner (CapitalBio Corp.) and the resulting images were analyzed with LuxScan ${ }^{\mathrm{TM}} 3.0$ software (CapitalBio Corp.). cDNA spots were screened and identified with the methods described by [77]. A spatial and intensity-dependent (LOWESS) normalization method was employed and normalized ratio data were then log transformed [79]. Differentially expressed genes were identified using a t-test, and multiple test corrections were performed using FDR. Genes with FDR $<0.05$ and a fold change $\geq 2$ were identified as differentially expressed genes.

All the clones differentially expressed in at least one of the four stages were subjected to single-pass sequence using standard high throughput sequencing by BGIWuhan, China. All sequences were edited to omit vectors and low quality segments at 5' and 3' ends, then removal of sequences shorter than 100 bp with SeqClean software. Sequence reads were assembled by CAP3 program [80] with default parameters. Then all the unigenes were annotated using BLASTx with a cut-off value of $1.0 \times \mathrm{e}^{-5}$ by searching the UniProt database (http://www. ebi.ac.uk/uniprot/). GO-KEGG-EC annotation was performed based on Annot8r platform [81]. Hierarchical clustering of transcript accumulation was performed with Cluster software (version 3.0) [82].

\section{Quantitative real-time PCR verification and candidate TFs analysis}

Total RNA was extracted from QS and EG collected at four different developmental stages with the Trizol 
methods mentioned above. Primer pairs were designed with the Primer Express software (Applied Biosystems, Foster City, CA, USA). Primer sequences of 11 candidate genes for verification were provided in Additional file 5: Table S1, and primer sequences of $10 \mathrm{TFs}$ were provided in Additional file 6: Table S2. Single strand cDNA was synthesized with the prescription of the Revert Aid TM first strand cDNA synthesis Kit (Fermentas, Life Science, $\mathrm{EU})$. Then each cDNA sample was pre-amplified using the citrus house-keeping gene $\beta$-actin and normalized for subsequent real-time quantitative PCR (qRT-PCR). The PCR program differed in terms of the annealing temperature of each primer pair and the length of the predicted PCR products. The qRT-PCR was performed using the ABI 7500 Real Time System (PE Applied Biosystems, Foster City, CA, USA) with the method as described by [83]. And relative transcript change was analyzed by $2^{-\Delta \Delta c(t)}$.

\section{Additional files}

Additional file 1: Figure S1. Comparison of expression patterns of 4 ESTs assembled the some contig encoding Methionine synthase. Y-axis represents the average Cy5 (Cy3) to Cy3 (Cy5) ratio in array hybridization. $X$-axis represents the four developmental stages.

Additional file 2: Figure S2. The correlation of gene expression ratios between CDNA microarray and qRT-PCR. Data were from 11 probe sets at four developmental stages. The gene expression ratios based on cDNA microarray were in log2 transformed.

Additional file 3: Sequences shorter than 200 bp but longer than 100 bp.

Additional file 4: Figure S3. The purified PCR products for microarray probe. 100 bp molecular ladders were used.

Additional file 5: Table S1. qRT-PCR primers for 11 candidate genes and citrus actin gene.

Additional file 6: Table S2. qRT-PCR primers for 10 transcription factors (TFs).

\section{Abbreviations}

AP2: APETALA2; AFLP: Amplified fragment length polymorphism; $\mathrm{C} 2 \mathrm{H} 2$ TF: Cys2His2 transcription factor; CBF: C-repeat DNA replication-related element binding factor; DREB: DNA replication-related element binding; ERF/ EREBPS: Ethylene-responsive element binding proteins; MSAP: Methylationsensitive amplification polymorphism; NAC TFs: (NAM, ATAF and CUC) transcription factors; qRT-PCR: Quantitative reverse transcription polymerase chain reaction; SCAR: Sequence characterized amplified region; SSR: Simple sequence repeat.

\section{Competing interests}

The authors declare that they have no competing interests.

\section{Authors' contribution}

WMQ performed the experiments and interpreted the results. ADZ carried out the ESTs annotation. YW helped with phenotype analysis. WMQ and WWG drafted the manuscript. LJC and XXG participated in the SSH-CDNA construction. XXD participated in research design. WWG proposed and supervised the overall project. All authors read and approved the final manuscript.

\section{Acknowledgements}

This research was financially supported by the Ministry of Science and Technology of China (nos. 2011CB100606, 2011AA100205), the National NSF of China, and the Ministry of Agriculture of China. The authors thank Professor Han-Hui Kuang (Huazhong Agric. Univ.) for his critical reading the manuscript.

Received: 27 March 2012 Accepted: 11 July 2012

Published: 16 August 2012

\section{References}

1. Varoquaux F, Blanvillain R, Delseny M, Gallois P: Less is better: new approaches for seedless fruit production. Trends Biotechnol 2000, 18:233-242.

2. Gillaspy G, Ben-David H, Gruissem W: Fruits: A developmental perspective. Plant Cell 1993, 5:1439-1451.

3. Weterings $K$, Russell SD: Experimental analysis of the fertilization process. Plant Cell 2004, 16:S107-S118.

4. Fos M, Proano K, Nuez F, Garcia-Martinez JL: Role of gibberellins in parthenocarpic fruit development induced by the genetic system pat-3/ pat-4 in tomato. Physiol Plant 2001, 111:545-550.

5. Dorcey E, Urbez C, Blazquez MA, Carbonell J, Perez-Amador MA: Fertilization-dependent auxin response in ovules triggers fruit development through the modulation of gibberellin metabolism in Arabidopsis. Plant J 2009, 58:318-332

6. Serrani JC, Carrera E, Ruiz-Rivero O, Gallego-Giraldo L, Peres LEP, GarciaMartinez JL: Inhibition of Auxin Transport from the Ovary or from the Apical Shoot Induces Parthenocarpic Fruit-Set in Tomato Mediated by Gibberellins. Plant Physiol 2010, 153:851-862.

7. Plackett AR, Thomas SG, Wilson ZA, Hedden P: Gibberellin control of stamen development: a fertile field. Trends Plant Sci 2011, 16:568-578.

8. Song S, Qi T, Huang H, Ren Q, Wu D, Chang C, Peng W, Liu Y, Peng J, Xie D: The Jasmonate-ZIM domain proteins interact with the R2R3-MYB transcription factors MYB21 and MYB24 to affect Jasmonate-regulated stamen development in Arabidopsis. Plant Cell 2011, 23:1000-1013.

9. Talon M, Gmitter FG Jr: Citrus genomics. Int J Plant Genomics 2008, 2008:528361.

10. Deng XX: Advances on citrus breeding in the world. Acta Hortic Sinica 2005, 32:1140-1146.

11. Garcia-Lor A, Garcia-Martinez JL, Perez-Amador MA: Identification of ovule and seed genes from Citrus clementina. Tree Genet Genomes 2011, 8:227-235.

12. Zheng TG, Qiu WM, Fan GE, Zheng BB, Guo WW: Construction and characterization of a cDNA library from floral organs and fruitlets of Citrus reticulata. Biol Plantarum 2011, 55:431-436.

13. Cai XD, Fu J, Deng XX, Guo WW: Production and molecular characterization of potential seedless cybrid plants between pollen sterile Satsuma mandarin and two seedy Citrus cultivars. Plant Cell Tiss Org 2007, 90:275-283.

14. Fu J, Peng ZJ, Cai XD, Guo WW: Regeneration and molecular characterization of interspecific somatic hybrids between Satsuma mandarin and two seedy sweet oranges for scion improvement. Plant Breeding 2011, 130:287-290.

15. Grosser JW, Gmitter FGJ: Protoplast fusion for production of tetraploids and triploids: applications for scion and rootstock breeding in citrus. Plant Cell Tiss Org 2011, 104:343-357.

16. Guo WW, Prasad D, Cheng YJ, Serrano P, Deng XX, Grosser JW: Targeted cybridization in citrus: transfer of Satsuma cytoplasm to seedy cultivars for potential seedlessness. Plant Cell Rep 2004, 22:752-758.

17. Vardi A, Levin I, Carmi N: Induction of seedlessness in citrus: From classical techniques to emerging biotechnological approaches. J Am Soc Hortic Sci 2008, 133:117-126.

18. Sun $K$, Hunt $K$, Hauser BA: Ovule abortion in Arabidopsis triggered by stress. Plant Physiol 2004, 135:2358-2367.

19. Mezzetti B, Landi L, Pandolfini T, Spena A: The defH9-iaaM auxinsynthesizing gene increases plant fecundity and fruit production in strawberry and raspberry. Biotechnol 2004, 4:4.

20. Costantini E, Landi L, Silvestroni O, Pandolfini T, Spena A, Mezzetti B: Auxin synthesis-encoding transgene enhances grape fecundity. Plant Physiol 2007, 143:1689-1694.

21. Hartley RW: Barnase and barstar. Expression of its cloned inhibitor permits expression of a cloned ribonuclease. J Mol Biol 1988, 202:913-915. 
22. Li DD, Shi W, Deng XX: Agrobacterium-mediated transformation of embryogenic calluses of Ponkan mandarin and the regeneration of plants containing the chimeric ribonuclease gene. Plant Cell Rep 2002, 21:153-156.

23. Hanania U, Velcheva M, Or E, Flaishman M, Sahar N, Perl A: Silencing of chaperonin 21, that was differentially expressed in inflorescence of seedless and seeded grapes, promoted seed abortion in tobacco and tomato fruits. Transgenic Res 2007, 16:515-525.

24. Hanania U, Velcheva M, Sahar N, Flaishman M, Or E, Degani O, Perl A: The ubiquitin extension protein S27a is differentially expressed in developing flower organs of Thompson seedless versus Thompson seeded grape isogenic clones. Plant Cell Rep 2009, 28:1033-1042.

25. Tan B, Li DL, Xu SX, Fan GE, Fan J, Guo WW: Highly efficient transformation of the GFP and MAC12.2 genes into precocious trifoliate orange (Poncirus trifoliata [L.] Raf), a potential model genotype for functional genomics studies in Citrus. Tree Genet Genomes 2009, 5:529-537.

26. Li X, Gao X, Wei Y, Deng L, Ouyang Y, Chen G, Zhang Q, Wu C: Rice APOPTOSIS INHIBITOR5 coupled with two DEAD-box adenosine 5'triphosphate-dependent RNA helicases regulates tapetum degeneration. Plant Cell 2011, 23:1416-1434

27. Zhang D, Liang W, Yin C, Zong J, Gu F: OsC6, encoding a lipid transfer protein, is required for postmeiotic anther development in rice. Plant Physiol 2010, 154:149-162.

28. Zhu J, Chen H, Li H, Gao JF, Jiang H, Wang C, Guan YF, Yang ZN: Defective in Tapetal development and function 1 is essential for anther development and tapetal function for microspore maturation in Arabidopsis. Plant J 2008, 55:266-277.

29. Dun X, Zhou Z, Xia S, Wen J, Yi B, Shen J, Ma C, Tu J, Fu T: BnaC.Tic40, a plastid inner membrane translocon originating from Brassica oleracea, is essential for tapetal function and microspore development in Brassica napus. Plant J 2011, 68:532-545.

30. Tang S, Hu B: Selecting of a seedless, good-quality and high-yield cultivar of ponkan-Qianyang seedless Ponkan. South China Fruits 2001, 30:3-6.

31. Xiao JP, Tan JJ, Liu HL, Chen LG, Ye WQ, Cheng WL: Studies on the seedless mechanism of Lipeng No. 2 Ponkan (Citrus reticulata). Journal of Fruit Science 2007, 24:421-426.

32. Diatchenko L, Lau YF, Campbell AP, Chenchik A, Moqadam F, Huang B, Lukyanov S, Lukyanov K, Gurskaya N, Sverdlov ED, Siebert PD: Suppression subtractive hybridization: a method for generating differentially regulated or tissue-specific CDNA probes and libraries. Proc Natl Acad Sci US A 1996, 93:6025-6030.

33. International Citrus Genome Consortium, Haploid Clementine Genome; 2011. http://int-citrusgenomics.org, http://www.phytozome.net/.

34. Gmitter FG Jr, Chen CX, Machado MA, de Souza AA, Ollitrault P, Froehlicher Y, Shimizu T: Citrus genomics. Tree Genet Genomes 2012, 8:611-626.

35. Coetzer N, Gazendam I, Oelofse D, Berger DK: SSHscreen and SSHdb, generic software for microarray based gene discovery: application to the stress response in cowpea. Plant Methods 2010, 6:10.

36. Hillmann A, Dunne E, Kenny D: CDNA amplification by SMART-PCR and suppression subtractive hybridization (SSH)-PCR. Methods Mol Biol 2009, 496:223-243.

37. Liu Q, Zhu A, Chai L, Zhou W, Yu K, Ding J, Xu J, Deng X: Transcriptome analysis of a spontaneous mutant in sweet orange [Citrus sinensis (L.) Osbeck] during fruit development. J Exp Bot 2009, 60:801-813.

38. Wu ZD, Soliman KM, Bolton JJ, Saba S, Jenkins JN: Identification of differentially expressed genes associated with cotton fiber development in a chromosomal substitution line (CS-B22sh). Funct Integr Genomic 2008, 8:165-174.

39. Gou X, Yuan T, Wei X, Russell SD: Gene expression in the dimorphic sperm cells of Plumbago zeylanica: transcript profiling, diversity, and relationship to cell type. Plant J 2009, 60:33-47

40. Breto MP, Ruiz C, Pina JA, Asins MJ: The diversification of Citrus clementina Hort. ex Tan., a vegetatively propagated crop species. Mol Phylogenet Evol 2001, 21:285-293.

41. Butelli E, Licciardello C, Zhang Y, Liu J, Mackay S, Bailey P, ReforgiatoRecupero G, Martin C: Retrotransposons control fruit-specific, colddependent accumulation of anthocyanins in blood oranges. Plant Cell 2012, 24:1242-1255.

42. Xiao JP, Chen LG, Xie M, Liu HL, Ye WQ: Identification of AFLP fragments linked to seedlessness in Ponkan mandarin (Citrus reticulata Blanco) and conversion to SCAR markers. Sci Hortic-Amsterdam 2009, 121:505-510.
43. Scott RJ, Spielman M, Dickinson HG: Stamen structure and function. Plant Cell 2004, 16(Suppl):S46-60.

44. Wu G: Amino acids: metabolism, functions, and nutrition. Amino Acids 2009, 37:1-17.

45. Forde BG, Lea PJ: Glutamate in plants: metabolism, regulation, and signalling. J Exp Bot 2007, 58:2339-2358.

46. Kusano M, Tabuchi M, Fukushima A, Funayama K, Diaz C, Kobayashi M, Hayashi N, Tsuchiya YN, Takahashi H, Kamata A, et al: Metabolomics data reveal a crucial role of cytosolic glutamine synthetase $1 ; 1$ in coordinating metabolic balance in rice. Plant J 2011, 66:456-466.

47. Gray BN, Yang H, Ahner BA, Hanson MR: An efficient downstream box fusion allows high-level accumulation of active bacterial betaglucosidase in tobacco chloroplasts. Plant Mol Biol 2011, 76:345-355.

48. Brzobohaty B, Moore I, Kristoffersen P, Bako L, Campos N, Schell J, Palme K: Release of active cytokinin by a beta-glucosidase localized to the maize root meristem. Science 1993, 262:1051-1054.

49. Gerardi C, Blando F, Santino A, Zacheo G: Purification and characterisation of a beta-glucosidase abundantly expressed in ripe sweet cherry (Prunus avium L.) fruit. Plant Sci 2001, 160:795-805.

50. Thorlby G, Fourrier N, Warren G: The SENSITIVE TO FREEZING2 gene, required for freezing tolerance in Arabidopsis thaliana, encodes a betaglucosidase. Plant Cell 2004, 16:2192-2203.

51. Munoz-Amatriain M, Svensson JT, Castillo AM, Close TJ, Valles MP: Microspore embryogenesis: assignment of genes to embryo formation and green vs. albino plant production. Funct Integr Genomics 2009, 9:311-323.

52. Lam HM, Peng SS, Coruzzi GM: Metabolic regulation of the gene encoding glutamine-dependent asparagine synthetase in Arabidopsis thaliana. Plant Physiol 1994, 106:1347-1357.

53. Olea F, Perez-Garcia A, Canton FR, Rivera ME, Canas R, Avila C, Cazorla FM, Canovas FM, de Vicente A: Up-regulation and localization of asparagine synthetase in tomato leaves infected by the bacterial pathogen Pseudomonas syringae. Plant Cell Physiol 2004, 45:770-780.

54. Hwang IS, An SH, Hwang BK: Pepper asparagine synthetase 1 (CaAS1) is required for plant nitrogen assimilation and defense responses to microbial pathogens. Plant J 2011, 67:749-762.

55. Maaroufi-Dguimi H, Debouba M, Gaufichon L, Clement G, Gouia H, Hajjaji A, Suzuki A: An Arabidopsis mutant disrupted in ASN2 encoding asparagine synthetase 2 exhibits low salt stress tolerance. Plant Physiol Biochem 2011, 49:623-628.

56. Yang SF, Hoffman NE: Ethylene Biosynthesis and its Regulation in Higher Plants. Annu Rev Plant Physiol 1984, 35:155-189.

57. Son GH, Wan J, Kim HJ, Nguyen XC, Chung WS, Hong JC, Stacey G: Ethylene-responsive element-binding factor 5, ERF5, is involved in chitininduced innate immunity response. Mol Plant Microbe Interact 2012, 25:48-60.

58. Moffat CS, Ingle RA, Wathugala DL, Saunders NJ, Knight H, Knight MR: ERF5 and ERF6 Play Redundant Roles as Positive Regulators of JA/Et-Mediated Defense against Botrytis cinerea in Arabidopsis. PLoS One 2012, 7:e35995.

59. Pan Y, Seymour GB, Lu C, Hu Z, Chen X, Chen G: An ethylene response factor (ERF5) promoting adaptation to drought and salt tolerance in tomato. Plant Cell Rep 2012, 31:349-360.

60. Bethke G, Unthan T, Uhrig JF, Poschl Y, Gust AA, Scheel D, Lee J: Flg22 regulates the release of an ethylene response factor substrate from MAP kinase 6 in Arabidopsis thaliana via ethylene signaling. Proc Natl Acad SCi U S A 2009, 106:8067-8072.

61. Haake V, Cook D, Riechmann JL, Pineda O, Thomashow MF, Zhang JZ: Transcription factor CBF4 is a regulator of drought adaptation in Arabidopsis. Plant Physiol 2002, 130:639-648.

62. Xiao H, Tattersall EA, Siddiqua MK, Cramer GR, Nassuth A: CBF4 is a unique member of the CBF transcription factor family of Vitis vinifera and Vitis riparia. Plant Cell Environ 2008, 31:1-10.

63. Lin RC, Park HJ, Wang HY: Role of Arabidopsis RAP2.4 in regulating lightand ethylene-mediated developmental processes and drought stress tolerance. Mol Plant 2008, 1:42-57.

64. Krishnaswamy S, Verma S, Rahman MH, Kav NN: Functional characterization of four APETALA2-family genes (RAP2.6, RAP2.6L, DREB19 and DREB26) in Arabidopsis. Plant Mol Biol 2011, 75:107-127.

65. Chandler JW, Cole M, Flier A, Grewe B, Werr W: The AP2 transcription factors DORNROSCHEN and DORNROSCHEN-LIKE redundantly control Arabidopsis embryo patterning via interaction with PHAVOLUTA. Development 2007, 134:1653-1662. 
66. Nag A, Yang Y, Jack T: DORNROSCHEN-LIKE, an AP2 gene, is necessary for stamen emergence in Arabidopsis. Plant Mol Biol 2007, 65:219-232.

67. Yang C, Xu Z, Song J, Conner K, Vizcay Barrena G, Wilson ZA: Arabidopsis MYB26/MALE STERILE35 regulates secondary thickening in the endothecium and is essential for anther dehiscence. Plant Cell 2007, 19:534-548.

68. Millar AA, Gubler F: The Arabidopsis GAMYB-like genes, MYB33 and MYB65, are MicroRNA-regulated genes that redundantly facilitate anther development. Plant Cell 2005, 17:705-721.

69. Higginson T, Li SF, Parish RW: AtMYB103 regulates tapetum and trichome development in Arabidopsis thaliana. Plant J 2003, 35:177-192.

70. Yang ZN, Zhang ZB, Zhu J, Gao JF, Wang C, Li H, Li H, Zhang HQ, Zhang S, Wang DM, et al: Transcription factor AtMYB103 is required for anther development by regulating tapetum development, callose dissolution and exine formation in Arabidopsis. Plant J 2007, 52:528-538.

71. Brownfield L, Hafidh S, Borg M, Sidorova A, Mori T, Twell D: A plant germline-specific integrator of sperm specification and cell cycle progression. PLoS Genet 2009, 5:e1000430.

72. Borg M, Brownfield L, Khatab H, Sidorova A, Lingaya M, Twell D: The R2R3 MYB Transcription Factor DUO1 Activates a Male Germline-Specific Regulon Essential for Sperm Cell Differentiation in Arabidopsis. Plant Cell 2011, 23:534-549.

73. Jung C, Seo JS, Han SW, Koo YJ, Kim CH, Song SI, Nahm BH, Choi YD, Cheong JJ: Overexpression of AtMYB44 enhances stomatal closure to confer abiotic stress tolerance in transgenic Arabidopsis. Plant Physiol 2008, 146:623-635.

74. Kirik V, Kolle K, Misera S, Baumlein H: Two novel MYB homologues with changed expression in late embryogenesis-defective Arabidopsis mutants. Plant Mol Biol 1998, 37:819-827.

75. Christianson JA, Wilson IW, Llewellyn DJ, Dennis ES: The low-oxygeninduced NAC domain transcription factor ANAC102 affects viability of Arabidopsis seeds following low-oxygen treatment. Plant Physiol 2009, 149:1724-1738.

76. Liu YZ, Liu Q, Tao NG, Deng XX: Efficient isolation of RNA from fruit peel and pulp of ripening navel orange (Citrus sinensis Osbeck). Journal of Huazhong Agricultural University 2006, 25:300-304.

77. Ouyang B, Yang T, Li HX, Zhang L, Zhang YY, Zhang JH, Fei ZJ, Ye ZB: Identification of early salt stress response genes in tomato root by suppression subtractive hybridization and microarray analysis. J Exp Bot 2007, 58:507-520

78. Guo Y, Guo HY, Zhang L, Xie HY, Zhao X, Wang FX, Li Z, Wang YH, Ma SL, Tao JP, et al: Genomic analysis of anti-Hepatitis B virus (HBV) activity by small interfering RNA and lamivudine in stable HBV-producing cells. J Virol 2005, 79:14392-14403.

79. Yang YH, Dudoit S, Luu P, Lin DM, Peng V, Ngai J, Speed TP: Normalization for CDNA microarray data: a robust composite method addressing single and multiple slide systematic variation. Nucleic Acids Res 2002, 30:e15.

80. Huang X, Madan A: CAP3: A DNA sequence assembly program. Genome Res 1999, 9:868-877.

81. Schmid R, Blaxter ML: annot8r: GO, EC and KEGG annotation of EST datasets. BMC Bioinforma 2008, 9:180.

82. Eisen MB, Spellman PT, Brown PO, Botstein D: Cluster analysis and display of genome-wide expression patterns. Proc Natl Acad Sci U S A 1998, 95:14863-14868

83. Liu Q, Xu J, Liu YZ, Zhao XL, Deng XX, Guo LL, Gu JQ: A novel bud mutation that confers abnormal patterns of lycopene accumulation in sweet orange fruit (Citrus sinensis L. Osbeck). J Exp Bot 2007, 58:4161-4171.

doi:10.1186/1471-2164-13-397

Cite this article as: Qiu et al:: Comparative transcript profiling of gene expression between seedless Ponkan mandarin and its seedy wild type during floral organ development by suppression subtractive hybridization and CDNA microarray. BMC Genomics 2012 13:397.

\section{Submit your next manuscript to BioMed Central and take full advantage of:}

- Convenient online submission

- Thorough peer review

- No space constraints or color figure charges

- Immediate publication on acceptance

- Inclusion in PubMed, CAS, Scopus and Google Scholar

- Research which is freely available for redistribution

Submit your manuscript at www.biomedcentral.com/submit
C Biomed Central 